\title{
Noninnocent Ligand Behavior in Diruthenium Complexes Containing a 1,3-Diethynylbenzene Bridge
}

\author{
Mark A. Fox,${ }^{\dagger}$ Julian D. Farmer, ${ }^{\dagger}$ Rachel L. Roberts, ${ }^{\dagger}$ Mark G. Humphrey, ${ }^{\ddagger}$ and \\ Paul J. Low ${ }^{*} \dagger$ \\ ${ }^{\dagger}$ Department of Chemistry, Durham University, South Road, Durham DH1 3LE, U.K., and ${ }^{\ddagger}$ Research School \\ of Chemistry, Australian National University, Canberra, Australian Capital Territory 0200, Australia
}

Received March 17, 2009

\begin{abstract}
Summary: The electronic structures of 1,3-\{trans-Cl(dppe $)_{2} \mathrm{RuC} \equiv \mathrm{C}_{2} \mathrm{C}_{6} \mathrm{H}_{4}$ (3) and $1,3-\left\{C p^{*}(\text { dppe }) \mathrm{RuC} \equiv \mathrm{C}\right\}_{2^{-}}$ $\mathrm{C}_{6} \mathrm{H}_{4}(4)$ in their available redox states have been investigated using a combination of $U V-v i s-n e a r-I R$ and IR spectroscopy and computational methods. In contrast to the case for closely related iron compounds, for the ruthenium complexes 3 and $\mathbf{4}$ the bridging aryl moiety is heavily involved in the oxidation process, and consequently descriptions of the electronic structures and electronic transitions in terms of the language developed for mixed-valence systems with clearly identifiable metal oxidation states are not appropriate. Consequently, the unique low-energy (near-IR) absorption bands observed for the asymmetric cations $[3]^{+}$and $[4]^{+}$are better described as arising from charge transfer transitions from a metal acetylide donor to a metal phenylacetylide acceptor rather than in terms of IVCT transitions.
\end{abstract}

Mixed-valence (MV) compounds of the type $\left[\mathrm{M}^{n} \mathrm{~L}_{n}\right](\mu$ bridge) $\left[\mathrm{M}^{n+1} \mathrm{~L}_{n}\right]$ have attracted attention for many reasons, not least of all as models through which to study fundamental aspects of the electron-exchange reaction. ${ }^{1}$ It is selfevident that an MV compound should feature an element in two (or more) identifiable and distinct oxidation states, yet in the case of many organometallic species the mixing of the metal $d$ orbitals with supporting $\pi$-donor or acceptor ligands can make assignments of true metal oxidation states difficult, or even irrelevant. Thus, while the iron acetylide compounds $\mathrm{Fe}(\mathrm{C} \equiv \mathrm{CPh})(\mathrm{dppe}) \mathrm{Cp}^{*}$ give rise to frontier orbitals with appreciable metal character ${ }^{2,3}$ and are therefore appropriate for the construction of organometallic MV compounds such as the weakly coupled class II system [1,3-\{C $\mathrm{Cp}^{*}(\mathrm{dppe})-$ $\left.\mathrm{FeC} \equiv \mathrm{C}{ }_{2} \mathrm{C}_{6} \mathrm{H}_{4}\right]^{+}, 4,5$ the aryl acetylide ligands in ruthenium

*To whom correspondence should be addressed. Fax: +44 191384 4737. Tel: +44 191334 2114. E-mail: p.j.low@durham.ac.uk.

(1) Day, P.; Hush, N. S.; Clark, R. J. H. Philos. Trans. R. Soc. London, Ser. A 2008, 366, 5.

(2) (a) Denis, R.; Toupet, L.; Paul, F.; Lapinte, C. Organometallics 2000, 19, 4240. (b) Paul, F.; Toupet, L.; Thepot, J. Y.; Costuas, K.; Halet, J.-F.; Lapinte, C. Organometallics 2005, 24, 5464. (c) Ghazala, S. I.; Paul, F.; Toupet, L.; Roisnel, T.; Hapiot, P.; Lapinte, C. J. Am. Chem. Soc. 2006, 128, 2463.

(3) Paul, F.; da Costa, G.; Bondon, A.; Gauthier, N.; Sinbandhit, S.; Toupet, L.; Costuas, K.; Halet, J.-F.; Lapinte, C. Organometallics 2007, 26,874 .

(4) (a) Weyland, T.; Lapinte, C.; Frapper, G.; Calhorda, M. J.; Halet, J.-F.; Toupet, L. Organometallics 1997, 16, 2024. (b) Weyland, T.; Costuas, K.; Toupet, L.; Halet, J.-F.; Lapinte, C. Organometallics 2000 , 19, 4228. (c) Weyland, T.; Ledoux, I.; Brasselet, S.; Zyss, J.; Lapinte, C. Organometallics 2000, 19, 5235 .

(5) Weyland, T.; Costuas, K.; Mari, A.; Halet, J.-F.; Lapinte, C. Organometallics 1998, 17, 5569 . complexes such as trans- $\mathrm{RuCl}(\mathrm{C} \equiv \mathrm{CPh})(\mathrm{dppe})_{2}$ (1) and $\mathrm{Ru}(\mathrm{C} \equiv \mathrm{CPh})(\mathrm{dppe}) \mathrm{Cp}^{*}(\mathbf{2})$ are redox noninnocent. ${ }^{6-9}$

Before detailed studies $^{6-9}$ of the electronic structures of $[1]^{+}$ and $[2]^{+}$were available, compounds such as 1,3-\{trans-Cl$(\mathrm{dppm})_{2} \mathrm{RuC} \equiv \mathrm{C}_{2} \mathrm{C}_{6} \mathrm{H}_{4},{ }^{10,11} \quad 1,3-\left\{\right.$ trans-Cl(dppm) ${ }_{2} \mathrm{RuC} \equiv \mathrm{C}_{2_{2}}$ $5-\mathrm{HC} \equiv \mathrm{CC}_{6} \mathrm{H}_{3},{ }^{12} \quad 1,3-\{\text { trans-Cl(dppe })_{2} \mathrm{RuC} \equiv \mathrm{C}_{2} 2_{-5}-\mathrm{HC} \equiv \mathrm{CC}_{6}-$ $\mathrm{H}_{3}{ }^{13}$ and $1,3-\left\{\mathrm{Cp}\left(\mathrm{PPh}_{3}\right)_{2} \mathrm{RuC} \equiv \mathrm{C}\right\}{ }_{2}-5-\mathrm{HC} \equiv \mathrm{CC}_{6} \mathrm{H}_{3}{ }^{12}$ had already been observed to oxidize in two sequential and wellseparated one-electron steps. On the assumption that the oxidation processes were metal-centered, the intermediate monocation states were described as $\mathrm{Ru}^{\mathrm{II} / \mathrm{III}}$ mixed-valence complexes. Although low-energy electronic transitions that could be ascribed to intervalence charge transfer were not observed in these early studies, on the basis of the electrochemical data, the monocations were taken as being further examples of weakly coupled (i.e., Robin-Day class II) MV systems. However, the thermodynamic stability of the mixed-valence state that is reflected in these electrochemical data is a sum of factors, including ion-pair interactions, intramolecular electrostatic factors, solvation energies, varying degrees of metal-ligand bond energies in the different metal oxidation states, and the like, in addition to the "resonance", or delocalization, term. ${ }^{14}$ In light of the different degrees of metal character in the redox-active orbitals of acetylide complexes based on $\mathrm{Fe}$ and $\mathrm{Ru}$, the current intense interest in the electronic structure of organometallic "mixed valence" compounds, and the potential complications in descriptions of these systems that arise from redox-active bridging (or ancillary) ligands, we have taken the opportunity to

(6) Fox, M. A.; Roberts, R. L.; Khairul, W. M.; Hartl, F.; Low, P. J. J. Organomet. Chem. 2007, 692, 3277.

(7) Paul, F.; Ellis, B. G.; Bruce, M. I.; Toupet, L.; Roisnel, T.; Costuas, K.; Lapinte, C. Organometallics 2006, 25, 649.

(8) Powell, C. E.; Cifuentes, M. P.; Morrall, J. P.; Stranger, R.; Humphrey, M. G.; Samoc, M.; Luther-Davies, B.; Heath, G. A. $J$. Am. Chem. Soc. 2003, 125, 602.

(9) Gauthier, N.; Tchouar, N.; Justaud, F.; Argouarch, G.; Cifuentes, M. P.; Toupet, L.; Touchard, D.; Halet, J.-F.; Rigaut, S.; Humphrey, M. G.; Costuas, K.; Paul, F. Organometallics 2009, 28, 2253.

(10) Beljonne, D.; Colbert, M. C. B.; Raithby, P. R.; Friend, R. H.; Brédas, J. L. Synth. Met. 1996, 81, 179.

(11) Colbert, M. C. B.; Lewis, J.; Long, N. J.; Raithby, P. R.; Younus, M.; White, A. J. P.; Williams, D. J.; Payne, N. N.; Yellowlees, L.; Beljonne, D.; Chawdhury, N.; Friend, R. H. Organometallics 1998, 17, 3034.

(12) Long, N. J.; Martin, A. J.; de Biani, F. F.; Zanello, P. J. Chem. Soc., Dalton Trans. 1998, 2017.

(13) (a) Hurst, S. K.; Cifuentes, M. P.; Humphrey, M. G. Organometallics 2002, 21, 2353. (b) Powell, C. E.; Hurst, S. K.; Morrall, J. P.; Cifuentes, M. P.; Roberts, R. L.; Samoc, M.; Humphrey, M. G. Organometallics 2007, 26, 4456

(14) D'Alessandro, D. D.; Keene, F. R. Chem. Soc. Rev. 2006, 35, 424. 

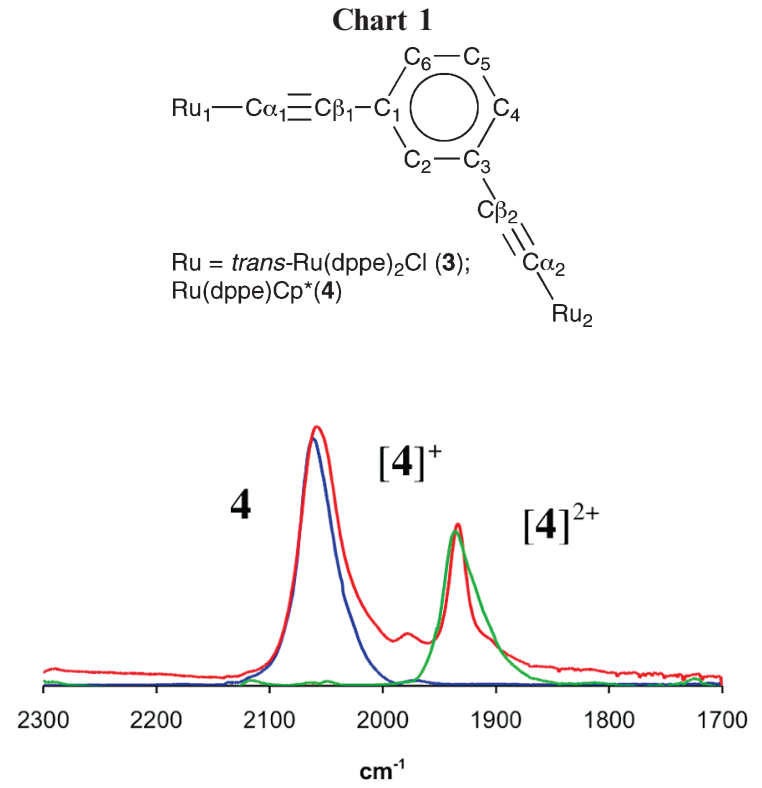

Figure 1. IR spectra of $\left[\left\{1,3-\mathrm{Cp}^{*}(\mathrm{dppe}) \mathrm{RuC} \equiv \mathrm{C}\right\}{ }_{2} \mathrm{C}_{6} \mathrm{H}_{4}\right]^{n+}$ $\left([4]^{n+}, n=0-2 ; \mathrm{CH}_{2} \mathrm{Cl}_{2} / 0.1 \mathrm{M}\left[\mathrm{NBu}_{4}\right] \mathrm{BF}_{4}\right.$, room temperature) collected from in situ oxidation in a spectroelectrochemical cell.

examine the electronic structures of $[3]^{n+}$ and $[4]^{n+}(n=0-2)$ (Chart 1).

The IR spectra of the new complexes 1,3-\{trans-Cl(dppe) ${ }_{2} \mathrm{RuC} \equiv \mathrm{C}_{2} \mathrm{C}_{6} \mathrm{H}_{4}(3)$ and $1,3-\{\mathrm{Cp} *(\text { dppe }) \mathrm{RuC} \equiv \mathrm{C}\}_{2} \mathrm{C}_{6} \mathrm{H}_{4}$ (4) are characterized by a single $v(\mathrm{C} \equiv \mathrm{C})$ band, coincidently at $2063 \mathrm{~cm}^{-1}$ in each case. The IR spectra of $[3]^{+}(v(\mathrm{C} \equiv \mathrm{C}) 2049$, $\left.1905 \mathrm{~cm}^{-1}\right)$ and $[4]^{+}\left(v(\mathrm{C} \equiv \mathrm{C}) 2060,1934 \mathrm{~cm}^{-1}\right)$ (Figure 1) each display two $v(\mathrm{C} \equiv \mathrm{C})$ bands, which approximate a superposition of the $v(\mathrm{C} \equiv \mathrm{C})$ bands in $\mathbf{1}\left(2075 \mathrm{~cm}^{-1}\right)$ and $[\mathbf{1}]^{+}\left(1910 \mathrm{~cm}^{-1}\right)$ or $\mathbf{2}$ $\left(2072 \mathrm{~cm}^{-1}\right)$ and [2] $]^{+}\left(1929 \mathrm{~cm}^{-1}\right)$, respectively. Further oxidation to $[3]^{2+}$ and $[4]^{2+}$ results in collapse of the characteristic twoband $v(\mathrm{C} \equiv \mathrm{C})$ pattern, and only a slightly broadened $v(\mathrm{C} \equiv \mathrm{C})$ band envelope is observed near $1900 \mathrm{~cm}^{-1}\left(v(\mathrm{C} \equiv \mathrm{C}):[3]^{2+}\right.$, $1909 \mathrm{~cm}^{-1} ;[4]^{2+}, 1938 \mathrm{~cm}^{-1}$ ).

Geiger has proposed a method of estimating a "charge distribution parameter", $\Delta \rho$, from IR spectroscopic data in redox-active bimetallic systems. ${ }^{15}$ The charge distribution parameter, which is a measure of the ground-state charge distribution between two redox centers in an intermediate oxidation state, is given by

$$
\Delta \rho=\frac{\left(\Delta v_{\mathrm{ox}}+\Delta v_{\mathrm{red}}\right)}{2\left(v_{\text {ox }}^{\prime}-v_{\text {red }}^{\prime}\right)}
$$

where $v_{\text {ox }}^{\prime}$ and $v_{\text {red }}^{\prime}$ are the wavenumbers of signature vibrational bands associated with the complex in the fully oxidized and fully reduced states (i.e., the dication and neutral complexes in the present examples), and $\Delta v_{\mathrm{ox}}=$ $v_{\text {ox }}^{\prime}-v_{\text {ox }}$ (obsd), $\Delta v_{\text {red }}=v_{\text {red }}^{\prime}-v_{\text {red }}$ (obsd). The parameters $\nu_{\text {ox }}$ (obsd) and $v_{\text {red }}$ (obsd) refer to the observed vibrational bands associated with the "oxidized" and "reduced" centers in the intermediate case. For $[3]^{+}$and $[4]^{+}, \Delta \rho=0.06$ and 0.03 , respectively, consistent with little ground-state interaction between the ethynyl groups.

(15) (a) Stoll, M. E.; Lovelace, S. R.; Geiger, W. E.; Schimanke, H.; Hyla-Kryspin, I.; Gleiter, R. J. Am. Chem. Soc. 1999, 121, 9343. (b) Atwood, C. G.; Geiger, W. E. J. Am. Chem. Soc. 2000, 122, 5477.
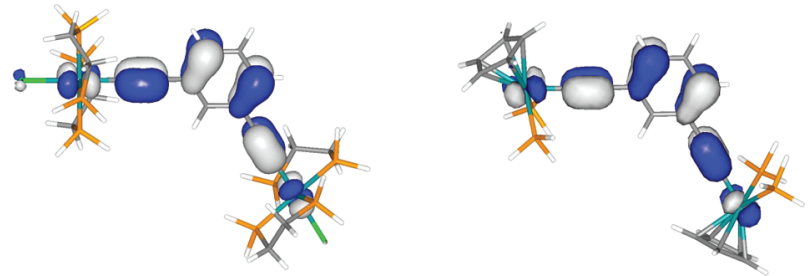

Figure 2. HOMO's of the neutral bimetallic model systems 3-H (left) and 4-H (right).

To better understand the electronic structures of $[3]^{n+}$ and $[4]^{n+}$, DFT calculations were carried out, ${ }^{16}$ using the model systems $\left[1,3-\left\{\text { trans }-\mathrm{Cl}(\mathrm{dHpe}){ }_{2} \mathrm{RuC} \equiv \mathrm{C}_{3} \mathrm{C}_{6} \mathrm{H}_{4}\right]^{n+}\left([3-\mathrm{H}]^{n+}\right)\right.$ and $\left[1,3-\left\{\mathrm{Cp}\left(\mathrm{PH}_{3}\right)_{2} \mathrm{RuC} \equiv \mathrm{C}_{2} \mathrm{C}_{6} \mathrm{H}_{4}\right]^{n+}\left([4-\mathrm{H}]^{n+}\right)\right.$ to reduce computational effort, but no symmetry constraints were applied. The calculated $v(\mathrm{C} \equiv \mathrm{C})$ frequencies are in good agreement with the observed data, giving confidence in the accuracy of the structural models. In the case of the neutral systems $\mathbf{3}$ and $\mathbf{4}$, differences in energy arising from different orientations of the metal fragments with respect to the plane of the aromatic ring are negligible, as has been found in related studies of $\mathbf{1}$ and 2. ${ }^{6,9}$ In each case the HOMO is $\mathrm{M}-$ $\mathrm{C}_{\alpha}$ antibonding, $\mathrm{C}_{\alpha}-\mathrm{C}_{\beta}$ bonding, and $\mathrm{C}_{\beta}-\mathrm{C}_{6} \mathrm{H}_{4}$ antibonding in character and, as with the mononuclear analogues, contains considerable diethynylbenzene character $\mathbf{3}-\mathbf{H}$, 76\%; 4-H, 73\%) (Figure 2).

The distinction of the metal sites and associated ligands implied by the IR $v(\mathrm{C} \equiv \mathrm{C})$ data is reproduced in the optimized geometries of $[3-\mathbf{H}]^{+}$and $[4-\mathbf{H}]^{+}$and calculated electronic structures. In comparison with the structures of the neutral, closed-shell bimetallic models $\mathbf{3}-\mathbf{H}$ and $\mathbf{4}-\mathbf{H}$, in each of the monocations $[3-\mathbf{H}]^{+}$and $[4-\mathbf{H}]^{+}$the local geometry around one of the metal ethynyl fragments (denoted $\mathrm{Ru}(1)$ for convenience) displays contracted $\mathrm{Ru}(1)-\mathrm{C}_{\alpha}(1)$ and $\mathrm{C}_{\beta}(1)-\mathrm{C}(1)$ bond lengths and elongated $\mathrm{C}_{\alpha}(1) \equiv \mathrm{C}_{\beta}(1)$ and $\mathrm{Ru}(1)-\mathrm{P}$ bond lengths. The local geometries associated with the $\mathrm{Ru}(1)$ metal center and the $\mathrm{Ru}(1)-\mathrm{C}_{\alpha}(1) \equiv \mathrm{C}_{\beta}(1)$ moieties in $[3-\mathbf{H}]^{+}$and $[\mathbf{4}-\mathbf{H}]^{+}$are essentially identical with those calculated for the mononuclear models $[\mathbf{1 - H}]^{+}$and $[\mathbf{2}-\mathbf{H}]^{+}$. The $\mathrm{Ru}(2)$ site, and associated $\mathrm{C}_{\alpha}(2) \equiv \mathrm{C}_{\beta}(2)$ moiety, is less significantly affected by the loss of electron density from the molecule and is closer in geometry to that calculated for $\mathbf{1 - H}$ or $\mathbf{2}-\mathbf{H}$. The calculated $v(\mathrm{C} \equiv \mathrm{C})$ frequencies from $[3-\mathbf{H}]^{+}$ $\left(2024,1935 \mathrm{~cm}^{-1}\right)$ and $[\mathbf{4 - H}]^{+}(2032,1944)$ accurately reproduce the two $v(\mathrm{C} \equiv \mathrm{C})$ bands observed experimentally.

For both $[3-\mathbf{H}]^{+}$and $[4-\mathbf{H}]^{+}$the $\beta$-LUSO is delocalized over the $\mathrm{Ru}(1)-\mathrm{C}_{\alpha}(1) \equiv \mathrm{C}_{\beta}(1)$ and the $\mathrm{C}(4)$ and $\mathrm{C}(6)$ carbon atoms of the bridging phenylene ring, while the $\beta$-HOSO has significant $\mathrm{Ru}(2)-\mathrm{C}_{\alpha}(2) \equiv \mathrm{C}_{\beta}(2)$ and $\mathrm{C}(2)$ character. The unpaired electron spin density in both $[3-\mathbf{H}]^{+}$and $[\mathbf{4 - H}]^{+}$is distributed over $\mathrm{Ru}(1)\left([3-\mathbf{H}]^{+},+0.28 ;[\mathbf{4}-\mathbf{H}]^{+},+0.36\right), \mathrm{C}_{\alpha}(1)$ $(+0.07 ;+0.02), \mathrm{C}_{\beta}(1)(+0.26 ;+0.31)$, and the aryl ring system $(+0.35 ;+0.31)$. Within the aryl ring, the electron density is not evenly distributed but, rather, is more concentrated at $\mathrm{C}(4)$ and $\mathrm{C}(6)$. The integrated electron density over the $\mathrm{Ru}(2)-\mathrm{C}_{\alpha}(2)-\mathrm{C}_{\beta}(2)$ fragment in $[3-\mathbf{H}]^{+}$and $[4-\mathbf{H}]^{+}$is only ca. $0.1-0.01$ e. Taken as a whole, the calculated geometry and spin density are consistent with the simple valence bond description shown in Scheme 1, in which the phenylene

(16) Fox, M. A.; Roberts, R. L.; Baines, T. E.; Le Guennic, B.; Halet, J.-F.; Hartl, F.; Yufit, D. S.; Albesa-Jové, D.; Howard, J. A. K.; Low, P. J. J. Am. Chem. Soc. 2008, 130, 3566. 

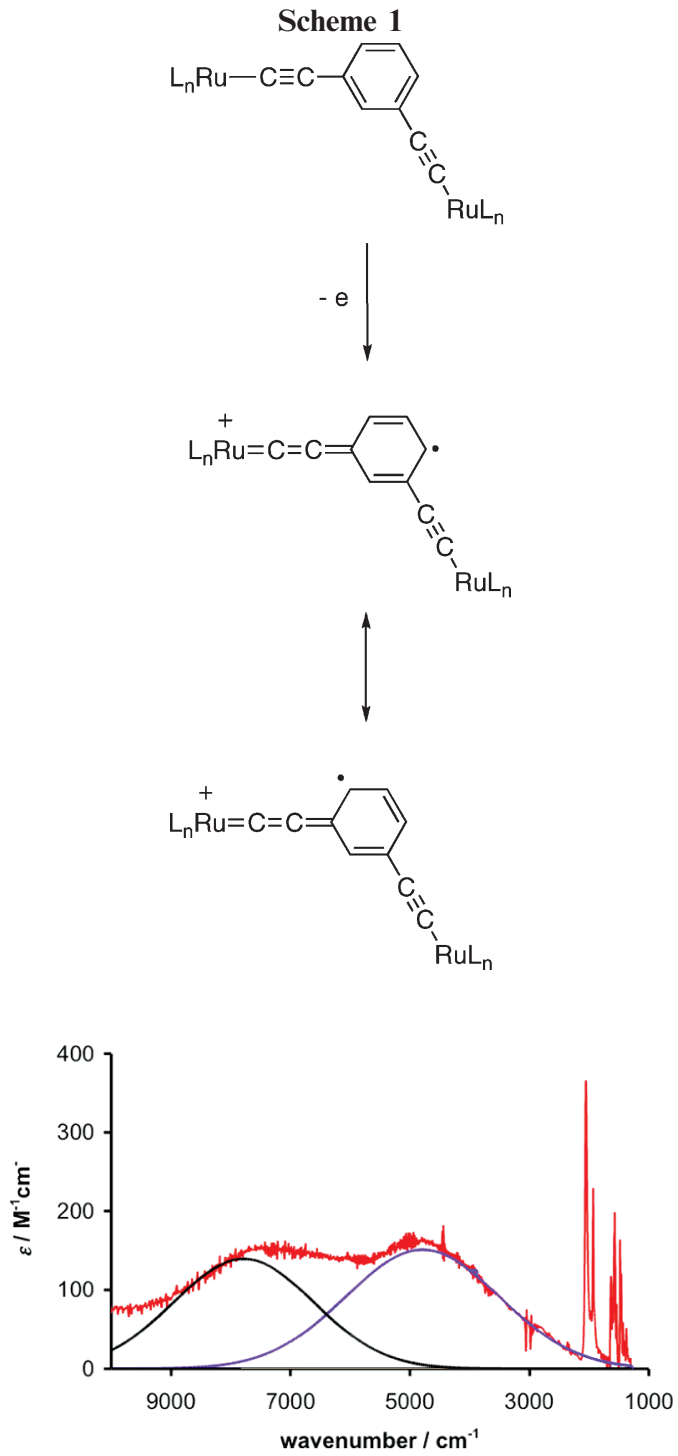

Figure 3. Near-IR-IR region of $[4]^{+}\left(\mathrm{CH}_{2} \mathrm{Cl}_{2} / 0.1 \mathrm{M}\left[\mathrm{NBu}_{4}\right]-\right.$ $\mathrm{BF}_{4}$ ), showing the deconvolution into a sum of two Gaussianshaped absorption bands.

ring plays an important role in the oxidation process. This important involvement of the $\mathrm{C}(1)-\mathrm{C}(6)$ aryl ring in stabilizing the unpaired electron is in contrast with the case for the related iron complex $\left[\left\{1,3-\mathrm{Cp} *(\mathrm{dppe}) \mathrm{FeC} \equiv \mathrm{C}_{3} \mathrm{C}_{6} \mathrm{H}_{4}\right]^{+}\right.$, in which localized $\mathrm{Fe}(\mathrm{II} / \mathrm{III})$ mixed-valence character has been demonstrated. $^{4 \mathrm{~b}}$

The thermodynamic stability of the electronically asymmetric monocations $[3]^{+}$and $[4]^{+}$implied by the solution electrochemical data (i.e., the significant separation of $E_{1}$ and $E_{2}$ and associated calculated $K_{\mathrm{C}}$ values) is reproduced by calculations on simplified, gas-phase model systems, suggesting that the stability is an inherent feature associated with delocalization of charge into the aromatic ring of the bridging ligand and is not just a consequence of external thermodynamic factors (e.g., ion pairing with the electrolyte ${ }^{17}$ ) or any significant charge delocalization between the metal centers (cf. the negligible $\Delta \rho$ values).

The near-IR regions of $[3]^{+}$and $[4]^{+}$feature weak absorption envelopes, each of which can be deconvoluted into two

(17) Barrière, F.; Geiger, W. E. J. Am. Chem. Soc. 2006, 128, 3980.
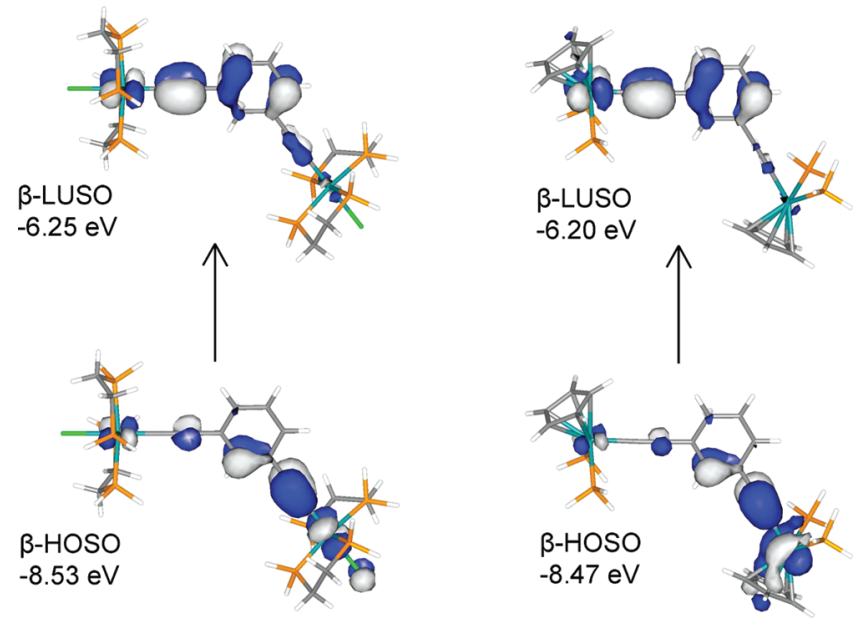

Figure 4. Frontier orbitals of the model systems $[3-\mathrm{H}]^{+}$(left) and $[4-\mathbf{H}]^{+}$(right) involved in the low-energy charge transfer bands observed experimentally for $[3]^{+}$and $[4]^{+}$.

Gaussian-shaped bands (Figure 3). The low intensity of these bands offers some explanation as to why near-IR bands were not observed in the electronic absorption spectrum of $\left[1,3-\left\{\text { trans }-\mathrm{Cl}(\mathrm{dppm})_{2} \mathrm{RuC} \equiv \mathrm{C}_{2} \mathrm{C}_{6} \mathrm{H}_{4}\right]^{+} .{ }^{11} \mathrm{On}\right.$ the basis of TD-DFT calculations, the lower energy, more intense near-IR band is attributed to the $\beta$-HOSO $\rightarrow \beta$-LUSO transition and clearly has charge-transfer characteristics arising from transitions from a metal acetylide donor to a metal phenylacetylide acceptor (Figure 4). The higher energy band arises from transitions between approximately orthogonal orbitals with $\mathrm{Ru}(\mathrm{d}) / \mathrm{C} \equiv \mathrm{C}(\pi)$ character. ${ }^{6}$ Therefore, the stabilization of the monocationic state arises from the delocalization of the unpaired electron in $[3]^{+}$and $[4]^{+}$between one metal center, the acetylide moiety, and the aromatic ring, rather than from delocalization of the charge between the two metal centers.

The charge-transfer near-IR bands in $[3]^{+}$and $[4]^{+}$collapse on further oxidation to $[3]^{2+}$ and $[4]^{2+}$, and while in the case of $[4]^{2+}$ the higher energy $(\mathrm{d} \pi-\mathrm{d} \pi)$ transition near $7500 \mathrm{~cm}^{-1}$ grows in intensity, in the case of [3] ${ }^{2+}$ transitions in this region are masked by the tail of the more intense chloride-to-metal LMCT band.

The dicationic compound $[3-\mathrm{H}]^{2+}$ offers both low-spin (LS) and high-spin (HS) electronic configurations. In their respective lowest energy conformations, the HS state, HS- $[3-\mathbf{H}]^{2+}$, is more stable than the LS configuration, LS- $[3-\mathbf{H}]^{2+}$, by some $35.5 \mathrm{kcal} \mathrm{mol}^{-1}$. Similar energetic preferences for the HS state have been found for $[4-\mathrm{H}]^{2+}\left(36.4 \mathrm{kcal} \mathrm{mol}^{-1}\right)$, and also in closely related iron compounds calculated using the B3LYP functional. ${ }^{5}$ Broadly, there is also a better agreement between the calculated vibrational features of the HS dications with those observed experimentally, and it is likely that the HS state dominates in solution. The UV-vis-near-IR spectra of the dications $[3]^{2+}$ and $[4]^{2+}$ are also similar to those of the monocations $[\mathbf{1}]^{+}$and $[\mathbf{2}]^{+}$, respectively, ${ }^{6-9}$ supporting the HS state of $[3]^{2+}$ and $[4]^{2+}$ being dominant in solution. The potential energy surfaces of HS-[3-H $]^{2+}$ and HS-[4-H $]^{2+}$ feature a large number of shallow energy minima differentiated by the orientation of the $\mathrm{RuP}_{4}$ and $\mathrm{RuP}_{2} \mathrm{Cp}$ fragments relative to the plane of the bridging phenylene ring. The most stable minima of HS-[3-H $]^{2+}$ and HS- $[\mathbf{4}-\mathbf{H}]^{2+}$ feature geometric parameters associated with the $\mathrm{Ru}-\mathrm{C}_{\alpha}-\mathrm{C}_{\beta}$ fragments similar to those found in the corresponding monoruthenium 
cations $[\mathbf{1 - H}]^{+}$and $[\mathbf{2 - H}]^{+}$, and there is no significant structural distinction between the $\mathrm{Ru}(1)-\mathrm{C}_{\alpha}(1) \equiv \mathrm{C}_{\beta}(1)$ and $\mathrm{Ru}-$ $(2)-\mathrm{C}_{\alpha}(2) \equiv \mathrm{C}_{\beta}(2)$ fragments in the dications.

In conclusion, the ruthenium complexes $\mathbf{3}$ and $\mathbf{4}$ feature redox noninnocent bridging ligands, with the physical properties of $[3]^{+}$and $[4]^{+}$being significantly influenced by the oxidized ligand. This is in contrast with the case found for the analogous iron systems, in which the predominantly metal centered frontier orbitals lead to redox products with more genuine "mixed valence" characteristics. ${ }^{4,5}$

Acknowledgment. This work was supported by a Durham University Doctoral Fellowship (J.D.F.) and the Australian Research Council (Discovery Grant to M.G.H., Linkage International Grant to M.G.H., R.L.R., and P.J.L., ARC Australian Professorial Fellowship to M.G.H., ARC International Fellowship to R.L.R.). We thank Durham University for access to its High Performance Computing Cluster.

Supporting Information Available: Text giving details of synthetic and other experimental procedures and computational methods and tables and plots summarizing observed and calculated $v(\mathrm{C} \equiv \mathrm{C})$ data, $\mathrm{UV}$-vis-near-IR data, redox potentials for $\mathbf{1 - 4}$, optimized geometries for $[\mathbf{1 - H}]^{n+}(n=0,1),[\mathbf{2}-\mathbf{H}]^{n+}(n=0$, $1),[3-\mathbf{H}]^{n+}(n=0-2)$, and $[\mathbf{4}-\mathbf{H}]^{n+}(n=0-2)$, calculated spin densities for $[\mathbf{1 - H}]^{+},[\mathbf{2}-\mathbf{H}]^{+},[3-\mathbf{H}]^{+},[\mathbf{4}-\mathbf{H}]^{+},[3-\mathbf{H}]^{2+}$, and $[4-$ $\mathbf{H}]^{2+}$, and composition of selected frontier orbitals. This material is available free of charge via the Internet at http://pubs. acs.org. 